\title{
Numerical simulation of foil with leading-edge tubercle for vertical-axis tidal-current turbine
}

\author{
I.K.A.P. Utama1', D. Satrio ${ }^{*}$, Mukhtasor ${ }^{1}$, M. Atlar ${ }^{2}$, W. Shi², R. Hantoro ${ }^{3}$ and G. Thomas ${ }^{4}$ \\ ${ }^{1}$ Faculty of Marine Technology, Institut Teknologi Sepuluh Nopember, 60111 Surabaya, Indonesia \\ Phone: +62315948757; Fax: +62315932104 \\ ${ }^{2}$ Faculty of Engineering, University of Strathclyde, G4 OLN Glasgow, United Kingdom \\ ${ }^{3}$ Faculty of Industrial Technology and Systems Engineering, Institut Teknologi Sepuluh Nopember, 60111 Surabaya, Indonesia \\ ${ }^{4}$ Faculty of Engineering Sciences, University College London, WC1E 7JHE London, United Kingdom
}

\begin{abstract}
The main disadvantage of the vertical-axis turbine is its low coefficient of performance. The purpose of this work was to propose a method to improve this performance by investigating the hydrodynamic forces and the flow-field of a foil that was modified with a sinusoidal leading-edge tubercle. NACA 63(4)021 was chosen as the original foil since it has a symmetrical profile that is suitable for use on a vertical-axis tidal-current turbine. The study was conducted using a numerical simulation method with ANSYS-CFX Computational Fluid Dynamics (CFD) code to solve the incompressible Reynolds-Averaged Navier-Stokes (RANS) equations. Firstly, the simulation results of the original foil were validated with available experimental data. Secondly, the modified foils, with three configurations of tubercles, were modelled. From the simulation results, the tubercle foils, when compared with the original foil, had similar lift performances at low Angles of Attack (0-8 degrees of AoA), lower lift performances at medium AoA (8-19 degrees) and higher lift performances at high AoA (19-32 degrees). A tubercle foil with Height/Chord $(H / C)$ of 0.05 can maintain the static stall condition until 32 degrees. Therefore, a vertical-axis turbine with tubercleblades provides an opportunity to increase its performance by extending the operational range for extracting energy in the dynamic stall condition.
\end{abstract}

ARTICLE HISTORY

Revised: $30^{\text {th }}$ Mar 2020

Accepted: $31^{\text {st }}$ Mar 2020

\section{KEYWORDS}

Foil simulation; leading-edge tubercle; computational fluid dynamics; vertical-axis turbine; tidal-current energy

\section{INTRODUCTION}

The tidal-current energy resource has generated significant interest in many countries around the world as a renewable energy source. Indonesia, as one of the largest archipelagic countries in the world, has a potential tidal-current energy resource of 17,898 MW [1, 2]. To harness this energy resource, there are several potential technologies including the vertical-axis turbine type. Most of the vertical-axis turbines have straight blades, known as the Darrieus turbine type [3]. However the main disadvantage of the vertical-axis turbine is a low coefficient of performance $\left(C_{P}\right)$ [4]. In an effort to improve the coefficient of performance, researchers have tried to modify the blade shape of vertical-axis turbine to be helical-blade [5], trapezoidal-blade [6], contra-rotating blade [7], cavity vane's geometry [8], hybrid Darrieus-Savonius [9], or even to be a blade with flexible material [10].

In the ocean there are many creatures that can be inspiring from an engineering perspective. One such animal is the humpback whale (Megaptera novaeangliae). Whilst this very large mammal has an approximate weight of 34 tonnes and a length of $15.6 \mathrm{~m} \mathrm{[11]}$, it has been found to swim and manoeuvre well in the ocean. One of the hypotheses for this good hydrodynamics performance is the bump on the flippers [12,13]. Aftab et al. [14] conducted a comprehensive review on tubercles on humpback whale flippers. This inspiring concept could be applied to the blade of vertical-axis turbine.

There are three constituent components that make a vertical-axis turbine: the foil, blade and rotor. In this study, the original blade shape of vertical-axis turbine (straight-blade) will be modified to be a tubercle-blade. A tubercle will be attached to the leading-edge of the blade with the expectation that it can increase the turbine performance. However, as a fundamental study to understand the working of this concept, this work will first focus on the foil simulation.

The flow field around a tubercle airfoil was investigated and explained that it resulted in significant span wise variation in all flow properties [15]. This argument was strengthened by other research that there was a vortex cancelation mechanism in the local trailing [16]. Then the tubercle concept was applied in a horizontal-axis tidal turbine [17]. Even though some numerical studies have been previous completed by other researchers [15, 16, 17], this study is important and required since it can give experience before directly simulating the turbine in rotating conditions.

The purpose of this work was to investigate the hydrodynamic forces and the flow-field of an original foil that was modified with a sinusoidal leading-edge tubercle. The tubercle design ratio of Width/Chord (W/C) was determined as 0.4 because it was the optimal result from the reference [18]. This study determines the best tubercle configuration of $H / C$ from the three given scenarios of $0.05,0.075$ and 0.1 . Then, the tubercle concept will be applied in vertical-axis turbine then checking its performance in the next work. 


\section{NUMERICAL SIMULATION}

\section{Geometry Inspired}

A humpback whale with its flippers is shown in Figure 1; every flipper has around 10 sinusoidal tubercles on its leading-edge [19]. A cross section of a flipper is shown in Figure 1 and is compared with a modern airfoil section NACA 63(4)021.

Vertical-axis tidal-current turbines usually have three blades, as also shown in Figure 1. A cross section of the verticalaxis turbine blade is given by a symmetrical foil without any modification. The foil sections types are generally NACA 0012, NACA 0018 and NACA 63(4)021. The symmetrical foil section is chosen to maintain the foil lift performance in each position when the turbine rotating. In this study, the NACA 63(4)021 was chosen since previous research has identified it as one of the best designs for vertical-axis turbines [20].

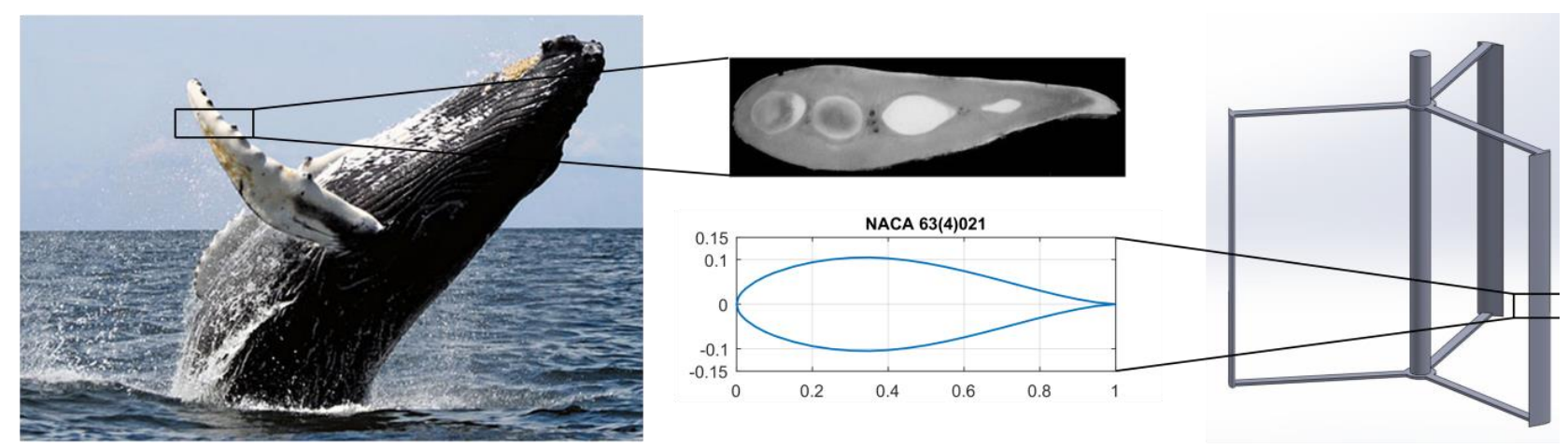

Figure 1. Cross section of a humpback whale flipper [18] and a foil on vertical-axis turbine

There are three design parameters to control the tubercle design: chord, width and height, as illustrated in Figure 2. In Table 1, some parameters have been determined from previous work [18] to produce a sound tubercle design. In this study, chord and width were with values of $1 \mathrm{~m}$ and $0.4 \mathrm{~m}$. The height parameter was varied to find the best combination for the tubercle design. The original foil profile has height parameter $(H)$ of $0 \mathrm{~m}$, whilst the tubercle foil profile has $H$ of $0.05,0.075$ and $0.1 \mathrm{~m}$. Therefore, the tubercle design ratio of $W / C$ is 0.4 and of $H / C$ are $0.05,0.075$ and 0.1 .

Table 1. Tubercle design parameters

\begin{tabular}{cccccc}
\hline Foil & $\begin{array}{c}\text { Chord } \\
C(\mathrm{~m})\end{array}$ & $\begin{array}{c}\text { Width } \\
W(\mathrm{~m})\end{array}$ & $\begin{array}{c}\text { Height } \\
H(\mathrm{~m})\end{array}$ & $W / C$ & $H / C$ \\
\hline NACA 63(4)021 & 1 & 0.4 & $0.05 ; 0.075 ; 0.1$ & 0.4 & $0.05 ; 0.075 ; 0.1$ \\
\hline
\end{tabular}

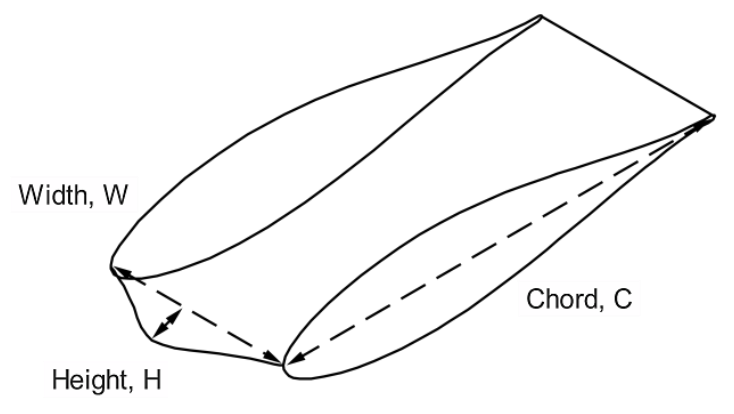

Figure 2. NACA 63(4)021 modified foil section with tubercle on the leading-edge

\section{Boundary Conditions in the Computational Domain}

In numerical work, besides the object geometry, the environment needs to be set to represent the fluid domain. A computational domain established as depicted in Figure 3, as a circle shape with diameter $(D)$ of $20 C$. The diameter size was chosen to ensure the domain independence based on the literature [17]. A circular shape was chosen because it is easier to control the AoA by changing the inlet velocity angle rather than with changing the foil position. The diameter was chosen to ensure that any vortex generated behind the foil was formed far away and the fluid flow was fully developed. The foil was located in the centre of the circle. 


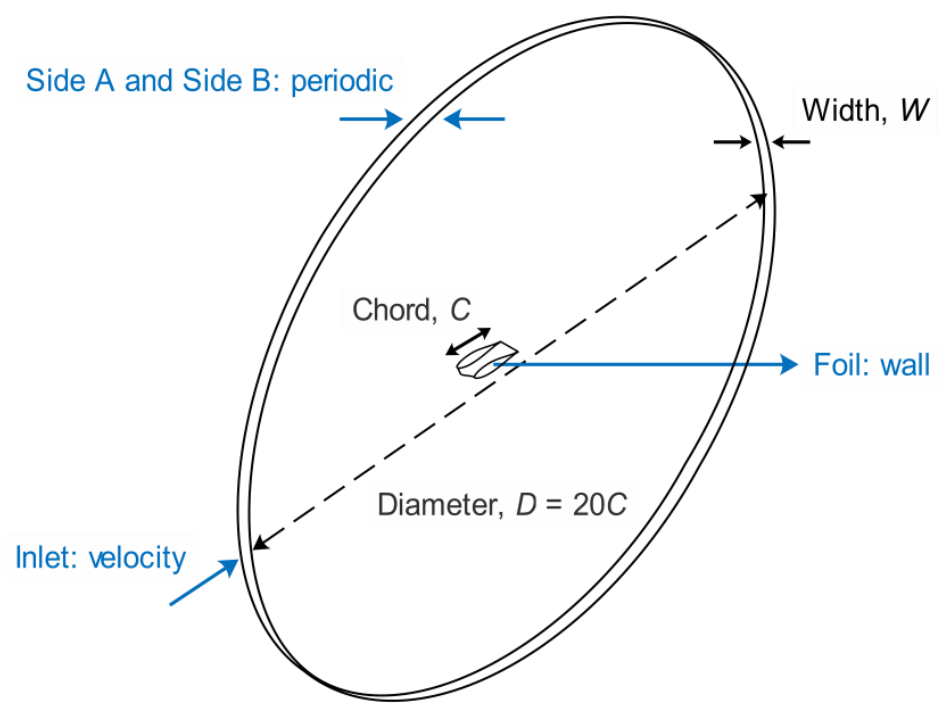

Figure 3. Computational domain and boundary conditions

The boundary conditions used in this simulation are depicted in Figure 3. The inlet boundary condition was set as a velocity inlet with a constant value of $0.1836 \mathrm{~m} / \mathrm{s}$. There was no outlet boundary condition because the circumference surface was set as inlet boundary condition that meant having a same direction of velocity vector. This value provided the same Reynolds number $(R e)$ value of 183,000 as for the reference experimental paper [18] and the experimental result of NACA 63(4)021 original foils was used for validation purpose. Sides A and B are defined as the periodic boundary conditions to accommodate vortex interaction between each side of the tubercle profile. The foil itself was defined as a wall with no slip conditions.

\section{Meshing Strategy}

Firstly, a mesh independence study was conducted to establish the correct number of mesh elements that could be used in all simulation setting. The NACA 63(4)021 original foil with AoA 12 degrees was used for this purpose. The results are shown in Figure 4 with the study starting with 500,000 elements then increasing gradually until 12,000,000 elements. As shown in Figure 4, the stability result achieved with 9,000,000 elements. However, for this study 12,000,000 elements were chosen to accommodate high AoA. At high AoA, the flow is no longer laminar anymore and a higher mesh density is needed to capture these phenomena of separation and turbulence.

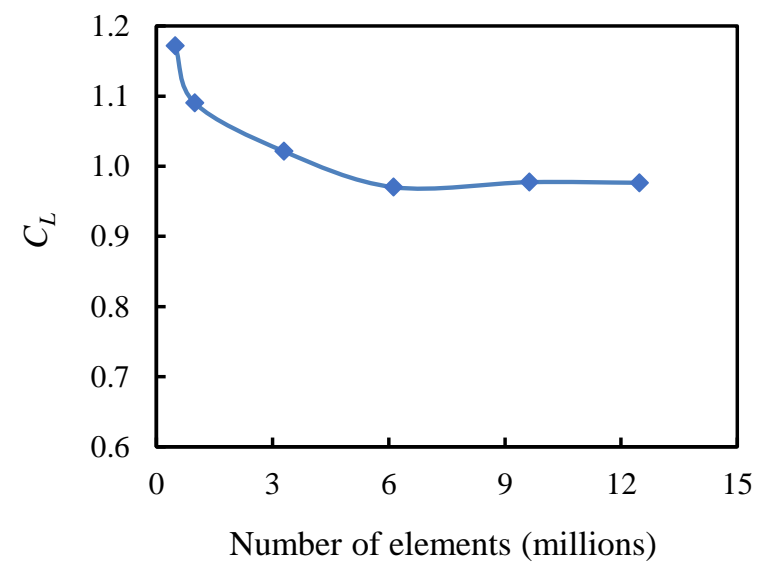

Figure 4. Mesh independence study of original foil at AoA 12 degrees

The mesh strategy used O-type unstructured mesh. Some elements sizing in foil edge, width edge and foil surface were implemented to control the mesh density. The mesh elements were distributed from the foil in the centre to edge of the circle as depicted in Figure 5. Body sizing was used to make the mesh denser around the foil, with approximately $80 \%$ of mesh elements close to the foil. 


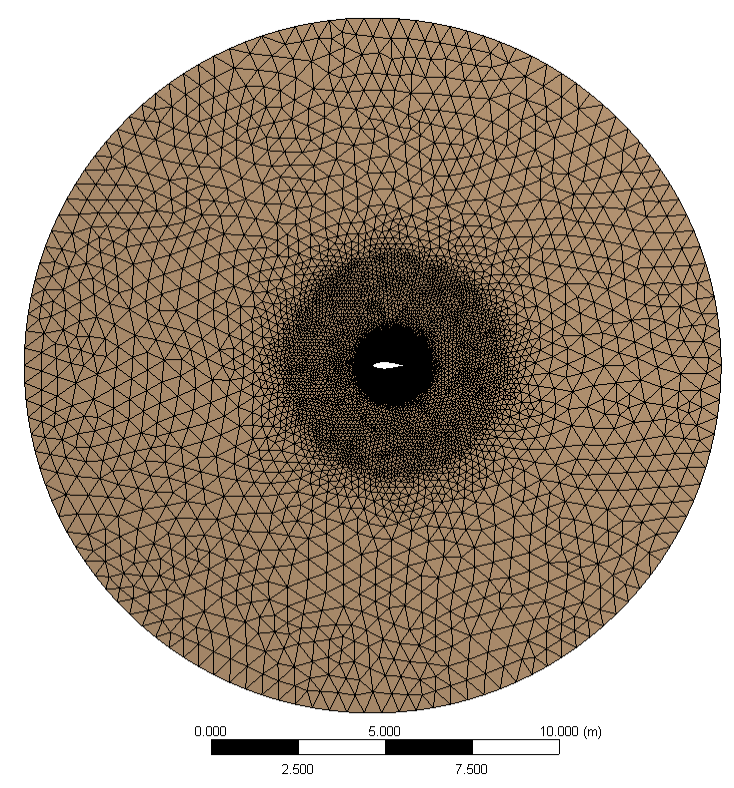

Figure 5. Overview of unstructured mesh on overall computational domain

The mesh near to the foil was refined as depicted in Figure 6, which shows a zoomed-in view to explain that this location required this treatment for resolving the boundary layer flows. The inflation layer strategy was implemented, with the non-dimensional wall distance $(y+)$ value for the first mesh being 0.99 regarding the Reynolds number value from the experiment and according to experience from previous studies [15, 17, 21]. The first mesh height was 1.1310 $4 \mathrm{~m}$ as calculated with the $y+$ equation.

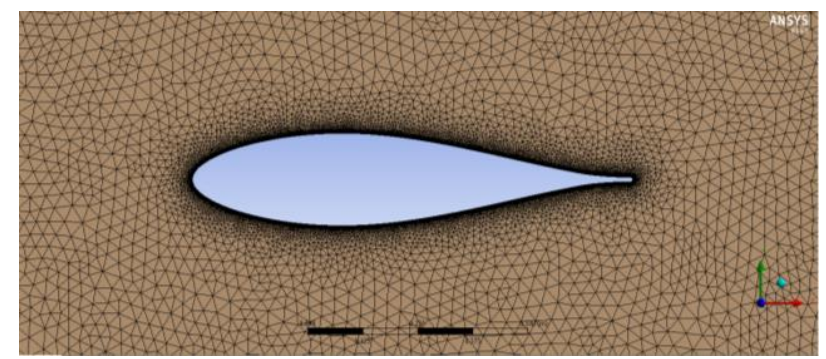

Figure 6. A zoomed-in view to show the refinement mesh in an area close to the foil surface

\section{Solver Setup}

The foil simulation was performed using the Computational Fluid Dynamics (CFD) software ANSYS-CFX [22]. The simulation used 8 cores internal parallel processing. The code was used to solve incompressible steady state of ReynoldsAveraged Navier-Stokes (RANS) equations as shown in Equation (1). The turbulence model used to compute Reynolds stress in the RANS equations was K- $\omega$ SST two equations this was selected because it has good accuracy in the bulk regions and in the boundary layer regions [7, 21, 23]. The spatial discretisation gradient used the finite volume method with least squares cells; all transport equations were set as second-order scheme.

$$
\rho\left(\frac{\partial u_{i}}{\partial t}\right)+\rho \frac{\partial}{\partial x_{j}}\left(\overline{u_{\imath}} \bar{u}_{j}\right)=-\frac{\partial p}{\partial x_{i}}+\mu\left(\frac{\partial}{\partial x_{i}}\left(\frac{\partial u_{i}}{\partial x_{j}}\right)\right)-\rho \frac{\partial}{\partial x_{j}}\left(\overline{u_{\imath}^{\prime} u_{j}^{\prime}}\right)
$$

Turbulence model is achieved through a numerical model to calculate the average random velocity $\left(\overline{u_{\imath}^{\prime} u_{\jmath}^{\prime}}\right)$ that occurs, better known as Reynolds-stress $\left(\tau_{i j}\right)$ which is shown in Equation (2).

$$
\tau_{i j}=-\overline{u_{\imath}^{\prime} u_{\jmath}^{\prime}}
$$




\section{RESULTS AND DISCUSSION}

\section{Numerical Validation of Original Foil}

Firstly the NACA 63(4)021 was simulated to allow for validation with experimental data conducted by Johari et al. [18]. These experiments were conducted in a water tunnel at the Naval Undersea Warfare Centre (NUWC). A fiber optic Laser Doppler Velocimetry (LDV) system was used to monitor the free stream velocity. The lift and drag force were measured with a load cell (relative uncertainties of less than 1\%) [18]. Figure 7 shows a comparison between the coefficient of lift and drag $\left(C_{L}\right.$ and $\left.C_{D}\right)$ for the original foil as determined by CFD and the experimental results. There is reasonable agreement between the numerical results and experimental data.

The numerical model follows the experimental data in the pre-stall regime ( 0 degree until 20 degrees) precisely. After that angle, the lift performance in the experimental data experiences sudden stall with increasing drag. However, the $C_{L}$ of the numerical result at 20 degrees experienced only a soft-stall, as also found by Shi et al. [17]. For this AoA, separation has commenced and the turbulence model could not accurately predict the $C_{L}$. On the other hand, the $C_{D}$ has a very good match compared with the experimental data.
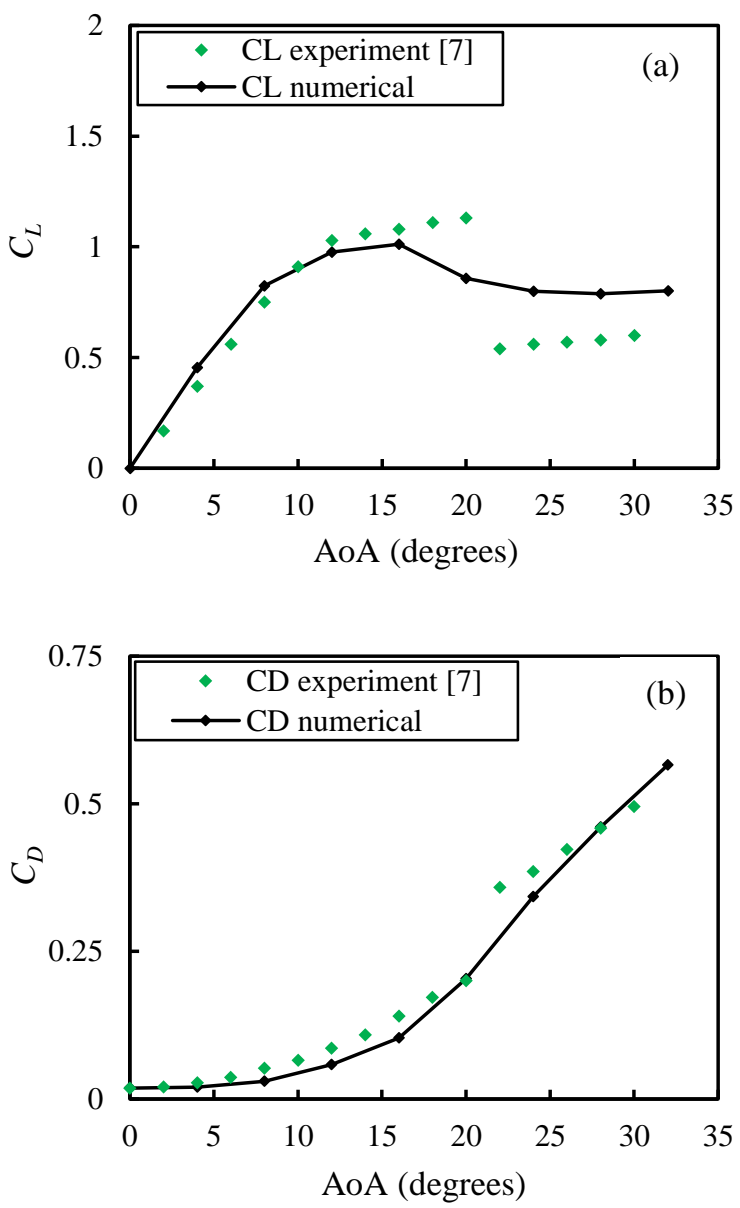

Figure 7. NACA 63(4)021 no tubercles: $C_{L}$ (a) and $C_{D}$ (b) for validation against experimental published data

The post-stall regime for the NACA 63(4)021 starts from 22 until 32 degrees. The $C_{D}$ of the numerical results follows the experimental trendline well. But again the $C_{L}$ of the numerical results experiences some over prediction. This result is logical because the foil simulation in high AoA (19-32 degrees) is difficult to produce since the turbulence phenomenon has already appeared. Compared with the experimental data, the numerical simulation results have a soft stall rather than a sharp stall. The foil simulation in the post-stall regime produces large scale flow structures being shed off behind the foil with large vortice sizes. There are two turbulence phenomena which are at the microscopic scale and flow structures scale. The steady state simulation with RANS models cannot capture these flow phenomena precisely, since the K- $\omega$ SST turbulence model is based around a single length scale being representative of the full turbulence spectrum.

\section{Numerical Simulation Results of Modified Foil}

Subsequently the numerical simulations were continued with the original foil modified in the leading-edge section with a tubercle profile. The numerical results of the modified foil with three given scenarios are shown in Figure 8 . The three scenarios of $H / C$ of $0.05,0.075$ and 0.1 were chosen based on the best experimental which was between $H / C$ of 
0.05 and 0.12 [18]. The tubercle with $H / C$ of 0.12 had a very sharp profile, therefore the maximum $H / C$ of 0.1 in this simulation is preferred.

The tubercle design ratio of $W / C$ was determined as 0.4 since the previous experimental data had already been completed with $W / C$ of 0.5 and 0.25 [18]. The tubercle with $W / C$ of 0.5 has a better lift in high AoA but lower lift at AoA 16-20 degrees. While the tubercle with $W / C$ of 0.25 , the lift has dropped significantly in AoA 26-30 degrees [18]. Therefore, a $W / C$ ratio of 0.4 was chosen.
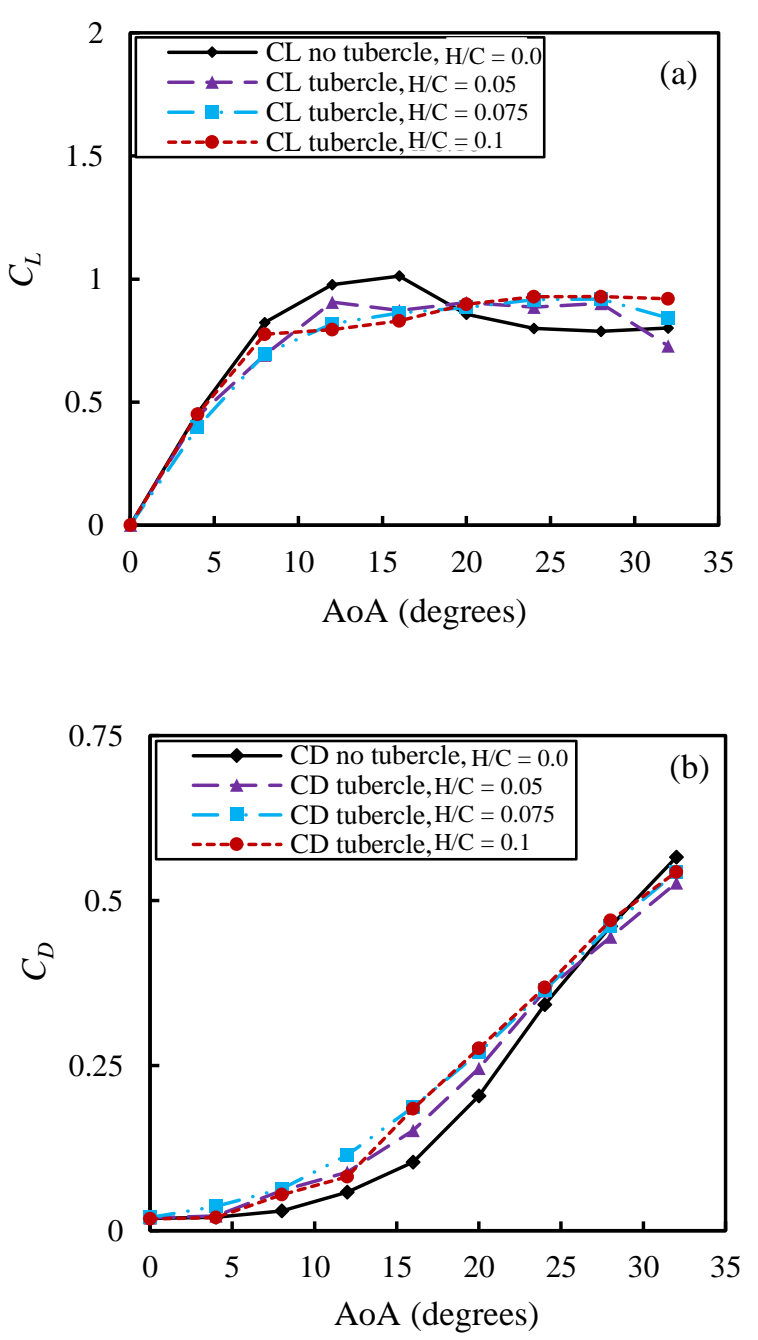

Figure 8. Numerical simulation results of NACA 63(4)021 with tubercles: $C_{L}$ (a) and $C_{D}$ (b)

The upper graph at Figure 8 shows $C_{L}$ versus AoA for both the original and modified foils. The lift performance for all foils increases with increasing AoA from 0 to 8 degrees (low AoA). Therefore, the tubercle foils have no effect at these AoA. Several references confirmed a similar effect on low AoA $[14,15,17]$. The $C_{L}$ of the original foil continues to increase until 16 degrees and for angles of attack 12 to 16 degrees, the original profile of NACA 63(4)021 has the best lift performance. However for the tubercle foil, the $C_{L}$ is starting to remain constant at lower angles than the original foil. From the simulation results, the $C_{L}$ is constant or flat from 8 to 16 degrees; therefore, the tubercle foil in this regime is not profitable. For angles of attack 20 to 30 degrees, the tubercle foil does not experience stall compared with the original foil and the $C_{L}$ continues to perform well until 32 degrees. The $C_{L}$ of the tubercle foils are higher than the original foil. This is the benefit of modified foil with tubercle, an effect that also occurs in an asymmetric foil [17].

The lower graph in Figure 8 shows $C_{D}$ for both original and modified foils. The drag performance for all cases also increased as increasing angle of attack increased from 0 to 8 degrees. The original foil continues to increase slightly until 20 degrees. However for the tubercle foil, the drag is higher than the original foil in the region 12 to 20 degrees. Experimental published data has confirmed this result [18]. Therefore, at these angles, the tubercle foils have lower $C_{L}$ because producing higher drag compared to the original foil. Continued to AoA 22 to 30 degrees, the $C_{D}$ remains the same when comparing the numerical and experimental data. Therefore, the tubercle foil can produce better lift in high AoA.

Both the $C_{L}$ and $C_{D}$ results in Figure 8 were processed to a normalisation curve in Figure 9. In Figure 9 there are four lines which are $H / C$ of 0.0 that represents the original foil and $H / C$ of $0.05,0.075$ and 0.1 that represent the tubercle foil. All $C_{L}$ and $C_{D}$ values of the numerical simulation results in varied AoA were divided by the value for the original foil 
value. Therefore, for $H / C$ of 0.0 , the curve is normalised to have a value of 1 . For $H / C$ of $0.05,0.075$ and 0.1 , the curve will be changes around value of 1 . The tubercle effect will be more visible compared with the original foil.
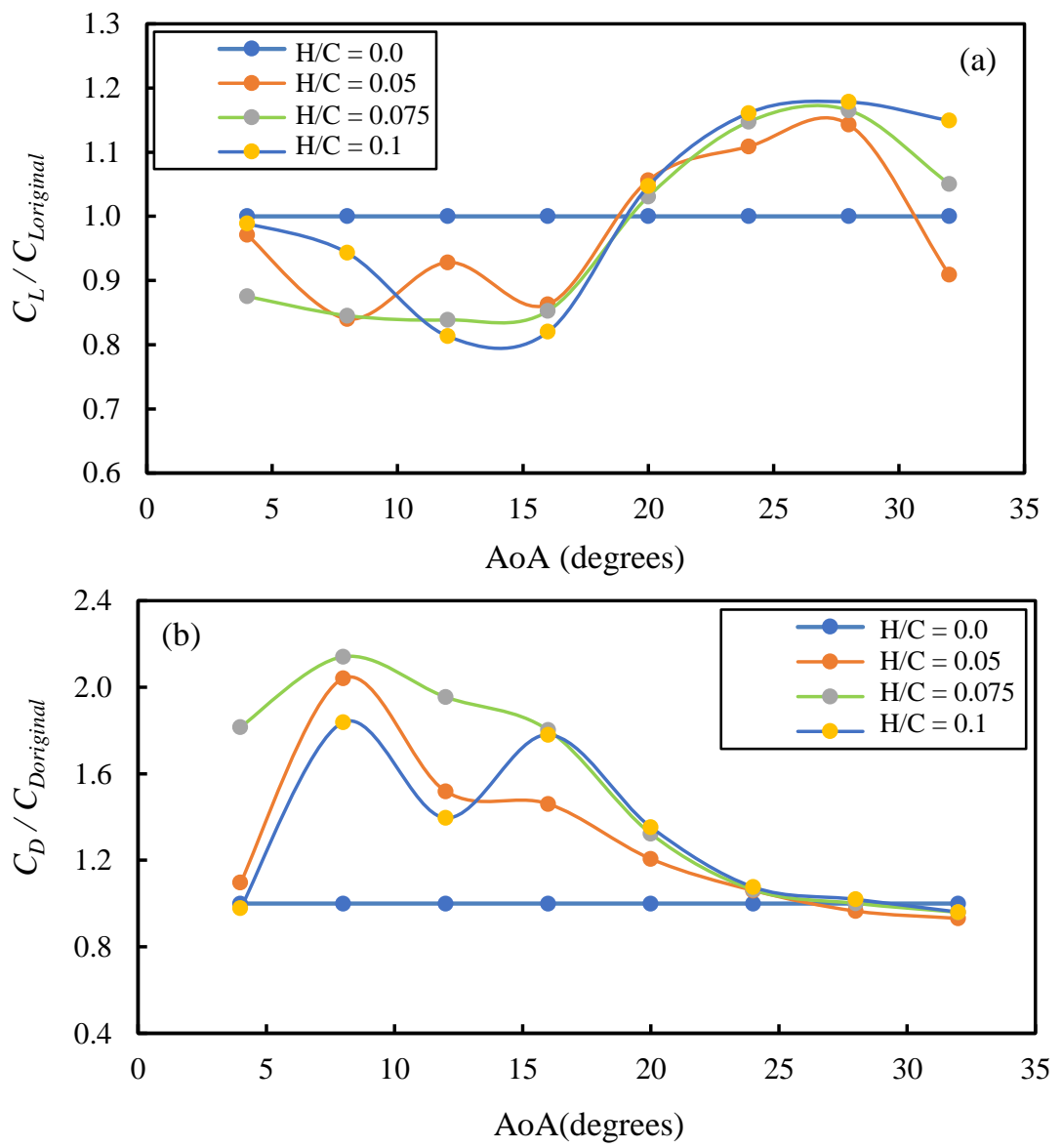

Figure 9. Normalisation curves of $C_{L}$ (a) and $C_{D}$ (b) compared with original foil

In the pre-stall regime ( 0 to 20 degrees), the tubercle foils have lower $C_{L}$. This occurs since in this regime the tubercle foils produces higher $C_{D}$ (Figure 9). The influence of different heights in the tubercle design have varying influence; whilst this influence cannot be clearly seen in this figure, it can be explained using the cross-plot graph in Figure 10.

In the post-stall regime (20 to 32 degrees), the tubercle foils have a similar $C_{D}$ compared with the original foil and the $C_{L}$ is higher than for the original foil. Reducing the height of the tubercle design influences the reduction in lift performance at AoA 32 degrees. The tubercle foil with $H / C$ of 0.1 maintains a strong $C_{L}$ value, however the tubercle foil with $H / C$ of 0.05 and 0.075 have a drop lift performance in AoA 32 degrees.

Figure 10 provides a cross-plot to see the effect of height on the lift performance of the tubercle foils. There are three different heights with five variations of AoA. AoA of 12 to 28 degrees are of particular interest since in this region the tubercle effect appears to be significant. The tubercle with $H / C$ of 0.05 has a $C_{L}$ around 0.9 in all variation of AoA. So the $C_{L}$ remains relatively constant and there are no significant changes. The tubercle with $H / C$ of 0.075 has increasing $C_{L}$ due to an increase of AoA. For example, the $C_{L}$ is 0.81 at 12 degrees and increases to 0.91 for an AoA of 28 degrees. The tubercle with $H / C$ of 0.1 has a large variation of $C_{L}$ with increasing AoA. In condition of low AoA, the $C_{L}$ will be very low (0.8) but in condition of high AoA, the $C_{L}$ will be higher than the other heights of tubercle design. It can be concluded that the tubercle foil with $H / C$ of 0.05 has a good chance for vertical-axis turbine because it can maintain the $C_{L}$ in all AoA. 


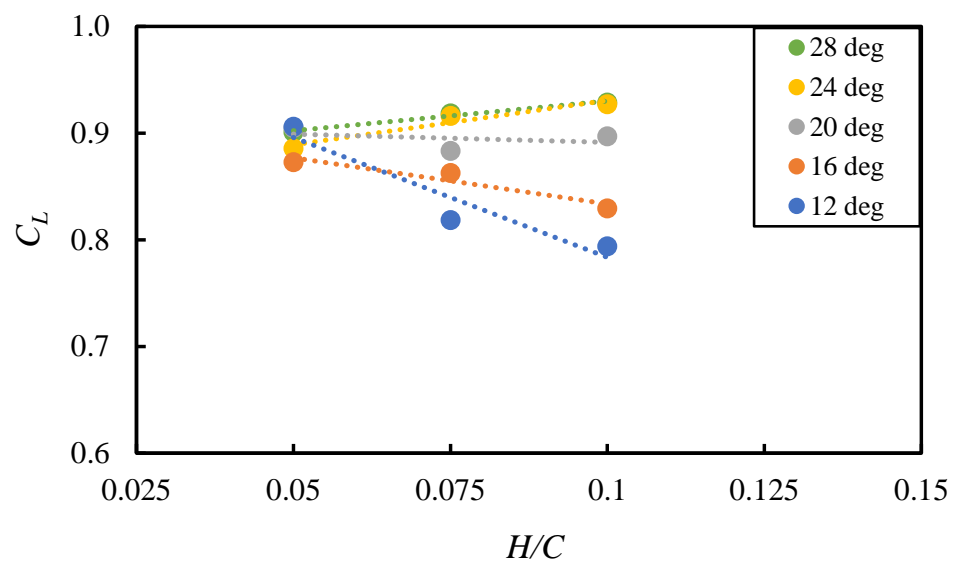

Figure 10. Cross-plot of coefficient of lift NACA 63(4)021 with tubercles in different height parameters

\section{Fluid Flow Visualisation: Streamline Contours}

Figures 11, 12 and 13 show streamline contours around the foils, both the NACA 63(4)021 original (a) and NACA 63(4)021 modified with tubercle (b). The streamline contour is used to explain the vorticity that form around the foil. AoA of 0,16 and 24 degrees were chosen to represent foil condition in zero AoA, pre-stall and post stall-regime for both the original and tubercle foil.

Figure 11 shows the streamline contours around the foil at 0 degree AoA. Both the original and tubercle foil have similar streamline contours, they are smooth with laminar flow over the foil surface. The tubercle profile at leading-edge section has no effect at this AoA.

Figure 12 shows the streamline contour around the foil at 16 degrees AoA. The original and tubercle foils have different streamline contours. The original foil has a laminar streamline contour passed the foil surface. However, the tubercle foil has a turbulence streamline contour. There is large vortex behind the foil in the upper surface position. This phenomenon explains why the tubercle foil has $C_{L}$ lower than the original foil in the pre-stall regime. This vorticity contributes to produce drag that reduces the lift performance.

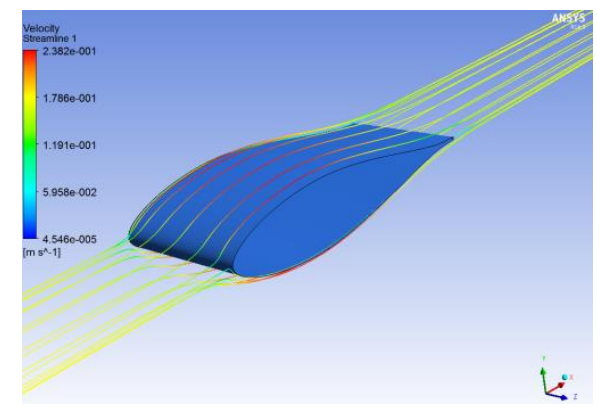

(a)

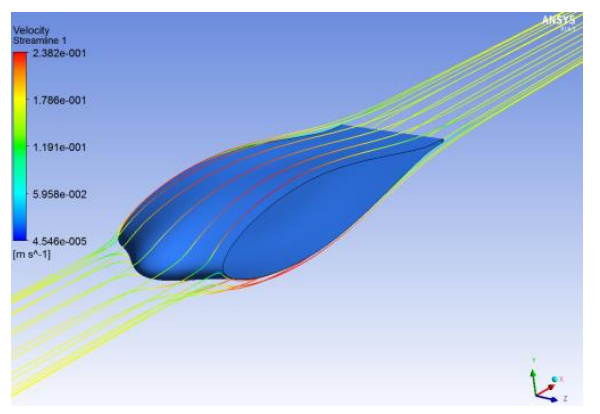

(b)

Figure 11. Streamline contours of original and modified foil at AoA 0 degree

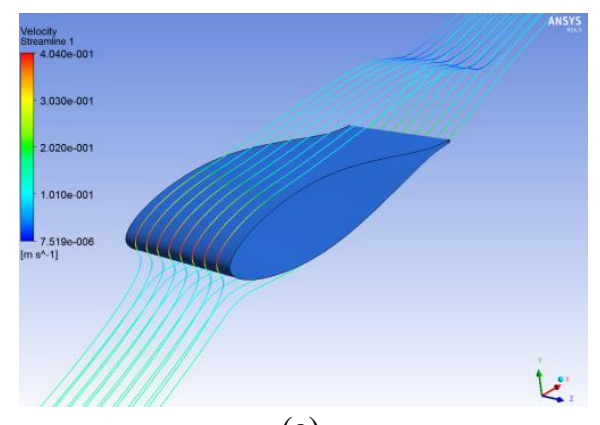

(a)

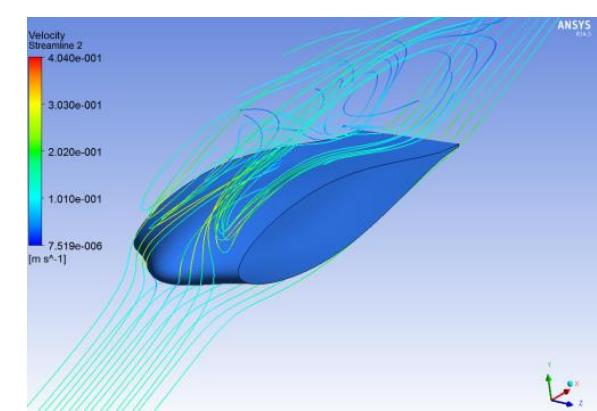

(b)

Figure 12. Streamline contours of original and modified foil at AoA 16 degrees 
Figure 13 shows the streamline contour around the foil at 24 degrees AoA. At this angle, both the original and tubercle foil are already in the post-stall regime, so there is turbulence phenomena that has formed behind the foil in the upper surface position. The original foil has a large turbulence streamline contour. However, the tubercle foil has two small turbulence streamline contours. The vorticity behind the foil is divided by the tubercle form at the leading-edge section; these two small vorticities have less effect on reducing $C_{L}$ rather than the single large vorticity. Therefore, this phenomenon explains why the tubercle foil has a $C_{L}$ higher than the original foil at this AoA. The tubercle foil can maintain the lift performance in high AoAs.

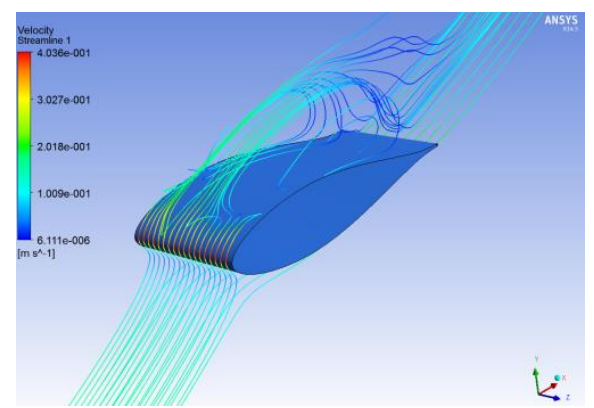

(a)

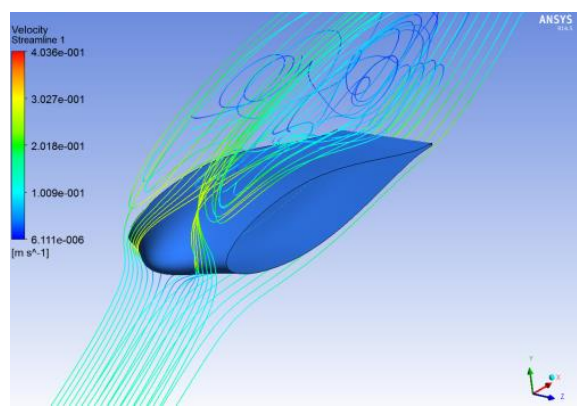

(b)

Figure 13. Streamline contours of original and modified foil at AoA 24 degrees

\section{Prospect of Tubercle Application in a Vertical-Axis Turbine}

Since the tubercle foils, when compared with the original foil, have a lower $C_{L}$ in low AoA, but maintain the $C_{L}$ in high AoA, the tubercle foil provides a good opportunity to increase the performance of vertical-axis tidal-current turbine. The illustration of changing the smooth surface of straight-blade to be tubercle-blade is shown in Figure 14. There is a strong correlation between the static stall that occurs in a foil and dynamic stall that occurs in a vertical-axis turbine. The static stall occurs in a foil due to changing AoA due to the inlet velocity. The dynamic stall occurs in a vertical-axis turbine due to the AoA and azimuth angle always changing due to the inlet velocity. The correlation is at Figure 14.
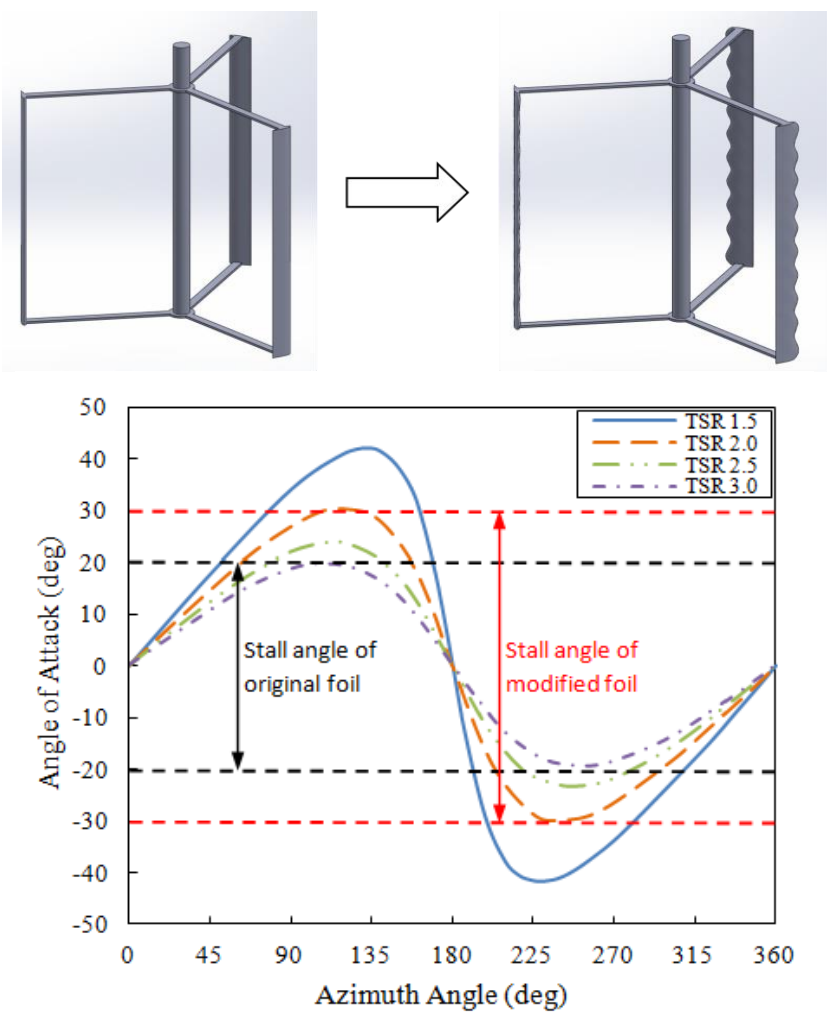

Figure 14. Correlation of static stall and dynamic stall when implementing tubercle foil concept into vertical-axis turbine

A vertical-axis rotates 360 degrees and operates normal to the incoming velocity of the tidal-current [4]. The position is represented by the azimuth angle $(\theta)$. Therefore the AoA of attack is changing for every position of azimuth angle. 
Moreover, the changing AoA also depends on the rotating velocity. Therefore in Figure 14 represents different tip speed ratios $(T S R)$. As the original foil has a static stall angle of 20 degrees, the energy extraction area is small. However, as the static stall increase to be 32 degrees (based on the result in this simulation), the energy extraction can be increased in the dynamic stall condition. Moreover, since this simulation is only limited until 32 degrees, the tubercle foil should be simulated at higher than 32 degrees to search for the possibility of maintaining the lift performance.

According to this analysis, there is a clear benefit to applying this tubercle concept in vertical-axis turbines. A verticalaxis turbine with a tubercle profile on the leading-edge of its blade is expected to increase the coefficient of performance, even though there are negative reports from other researchers that this idea is not profitable [24, 25, 26]. Whilst in contrast, there is also research that reports such foils have a positive effect [27, 28]. Regarding the results of this study, there is a hypothesis that the opportunities are very promising regarding the lift behaviour, since it is increased significantly in high AoA. The blades of a vertical-axis turbine always change AoA in each position of azimuth angle. The change in both AoA and azimuth angle can also be influenced by the platform motion [29]. Application of this tubercle can delay the static stall that affected on delaying the dynamic stall performance. Therefore, the opportunity for increasing the verticalaxis turbine performance is significant.

\section{CONCLUSIONS}

Simulations of performance of both original and modified with tubercle foils in pre-stall and post-stall regime have been carried out. The simulation results of NACA 63(4)021 original foil are consistent with available experimental data. Modification with tubercle profile on the leading-edge foil section is shown to be able to delay static stall angle at high AoA (19-32 degrees). A tubercle with $H / C$ of 0.05 can maintain the lift performance until 32 degrees. Therefore, a vertical-axis turbine with tubercle-blades provides an opportunity to increase the vertical-axis turbine performance by increasing the range operation of extracting energy in dynamic stall condition from 20 to 32 degrees.

Further investigation should be conducted to investigate the possibility of the tubercle to maintain the lift performance in AoA higher than 32 degrees. Also in the future work, it is planned to experimentally test this tubercle concept on the vertical-axis turbine blade to investigate the effect on its performance.

\section{ACKNOWLEDGMENTS}

The authors would like to convey their appreciation to the Directorate General of Resources for Science, Technology and Higher Education; Ministry of Research, Technology and Higher Education, the Republic of Indonesia, which funded the current project partly under a scheme called The Education of Master Degree Leading to Doctoral Program for Excellent Graduates (PMDSU) under contract number 803/PKS/ITS/2018, a scheme called World Class Professor Program under contract number 2019/PKS/ITS/2018 and a scheme called Competitive Research Program under contract number 847/PKS/ITS/2019.

\section{REFERENCES}

[1] Mukhtasor, Introduction to Ocean Energy (in Indonesian language). Surabaya: ICEES, 2014.

[2] Mukhtasor et al., "Indonesia Ocean Energy Potential Resources (in Indonesian language)," Badan Litbang Kementrian Energi dan Sumber Daya Mineral (ESDM) and Asosiasi Energi Laut Indonesia (ASELI), Jakarta, 2014.

[3] M. J. Khan, G. Bhuyan, M. T. Iqbal, and J. E. Quaicoe, "Hydrokinetic energy conversion systems and assessment of horizontal and vertical axis turbines for river and tidal applications: A technology status review," Appl. Energy, vol. 86, no. 10, pp. 18231835, 2009, doi: 10.1016/j.apenergy.2009.02.017.

[4] D. Satrio, I. K. A. P. Utama, and Mukhtasor, "Vertical Axis Tidal Current Turbine: Advantages and Challenges Review," in Proceeding of Ocean, Mechanical and Aerospace -Science and Engineering-, 2016, vol. 3, pp. 64-71, [Online]. Available: http://isomase.org/OMAse/Vol.3-2016/Section-1/3-7.pdf.

[5] A. N. Gorban, A. M. Gorlov, and V. M. Silantyev, "Limits of the turbine efficiency for free fluid flow," J. Energy Resour. Technol. Trans. ASME, vol. 123, no. 4, pp. 311-317, 2001, doi: 10.1115/1.1414137.

[6] J. Zanette, D. Imbault, and A. Tourabi, “A design methodology for cross flow water turbines," Renew. Energy, vol. 35, no. 5, pp. 997-1009, 2010, doi: 10.1016/j.renene.2009.09.014.

[7] D. Satrio, I. K. A. P. Utama, and Mukhtasor, "Numerical Investigation of Contra Rotating Vertical-Axis Tidal-Current Turbine," J. Mar. Sci. Appl., vol. 17, no. 2, pp. 208-2015, 2018, doi: 10.1007/s11804-018-0017-5.

[8] S. Ashwindran, A. A. Azizuddin, and A. N. Oumer, "Computational fluid dynamic (CFD) of vertical-axis wind turbine: mesh and time-step sensitivity study," J. Mech. Eng. Sci., vol. 13, no. 3, pp. 5604-5624, Sep. 2019, doi: 10.15282/jmes.13.3.2019.24.0450.

[9] D. Puspitasari and K. Sahim, "Effect of Savonius blade height on the performance of a hybrid Darrieus-Savonius wind turbine," J. Mech. Eng. Sci., vol. 13, no. 4, pp. 5832-5847, Dec. 2019, doi: 10.15282/jmes.13.4.2019.09.0465.

[10] D. H. Zeiner-Gundersen, "A novel flexible foil vertical axis turbine for river, ocean, and tidal applications," Appl. Energy, vol. 151, pp. 60-66, 2015, doi: 10.1016/j.apenergy.2015.04.005. 
[11] J. H. Johnson and A. A. Wolman, “The humpback whale, Megapteranovaeangliae,” Mar. Fish., vol. 4, pp. 30-37, 1984.

[12] F. E. Fish and J. M. Battle, "Hydrodynamic Design of the Humpback Whale Flipper," J. Morphol., vol. 225, pp. 51-60, 1995.

[13] P. Watts and F. E. Fish, "The influence of passive, leading edge tubercles on wing performance," Proc. Twelfth Intl. Symp. Unmanned Untethered Submers. Technol., Durham New Hampsh., no. May, pp. 2-9, 2001, [Online]. Available: http://www.otherpower.com/images/scimages/2637/leading_edge_tubercles.pdf.

[14] S. M. A. Aftab, N. A. Razak, A. S. Mohd Rafie, and K. A. Ahmad, "Mimicking the humpback whale: An aerodynamic perspective," Prog. Aerosp. Sci., vol. 84, pp. 48-69, 2016, doi: 10.1016/j.paerosci.2016.03.002.

[15] A. Dropkin, D. Custodio, C. W. Henoch, and H. Johari, "Computation of flowfield around an airfoil with leading-edge protuberances," J. Aircr., vol. 49, no. 5, pp. 1345-1355, 2012, doi: 10.2514/1.C031675.

[16] T. Swanson and K. M. Isaac, "Biologically inspired wing leading edge for enhanced wind turbine and air craft performance," in Proceedings of 6th AIAA Theo-retical Fluid Mechanics Conference, 2011, no. June, pp. 1-10.

[17] W. Shi, M. Atlar, R. Norman, B. Aktas, and S. Turkmen, "Numerical optimization and experimental validation for a tidal turbine blade with leading-edge tubercles," Renew. Energy, vol. 96, pp. 42-55, 2016, doi: 10.1016/j.renene.2016.04.064.

[18] H. Johari, C. Henoch, D. Custodio, and A. Levshin, "Effects of leading-edge protuberances on airfoil performance," AIAA J., vol. 45, no. 11, pp. 2634-2642, 2007, doi: 10.2514/1.28497.

[19] F. E. Fish, L. E. Howle, and M. M. Murray, "Hydrodynamic flow control in marine mammals," Integr. Comp. Biol., vol. 48, no. 6, pp. 788-800, 2008.

[20] G. W. Rawlings, "Parametric characterization of an experimental vertical axis hydro turbine," University of British Columbia, 2008.

[21] D. Satrio, I. K. A. P. Utama, and Mukhtasor, "The influence of time step setting on the CFD simulation result of vertical axis tidal current turbine," J. Mech. Eng. Sci., vol. 12, no. 1, pp. 3399-3409, 2018, doi: 10.15282/jmes.12.1.2018.9.0303.

[22] ANSYS, Ansys CFX-Solver Theory Guide. USA: SAS IP Inc., 2011.

[23] P. Marsh, D. Ranmuthugala, I. Penesis, and G. Thomas, "The influence of turbulence model and two and three-dimensional domain selection on the simulated performance characteristics of vertical axis tidal turbines," Renew. Energy, vol. 105, pp. 106-116, 2017, doi: 10.1016/j.renene.2016.11.063.

[24] C. J. Bai, Y. Y. Lin, S. Y. Lin, and W. C. Wang, "Computational fluid dynamics analysis of the vertical axis wind turbine blade with tubercle leading edge," J. Renew. Sustain. Energy, vol. 7, no. 3, 2015, doi: 10.1063/1.4922192.

[25] S. Y. Lin, Y. Y. Lin, C. J. Bai, and W. C. Wang, "Performance analysis of vertical-axis-wind-turbine blade with modified trailing edge through computational fluid dynamics," Renew. Energy, vol. 99, pp. 654-662, 2016, doi: 10.1016/j.renene.2016.07.050.

[26] I. C. M. Lositaño and L. A. M. Danao, "Steady wind performance of a $5 \mathrm{~kW}$ three-bladed H-rotor Darrieus Vertical Axis Wind Turbine (VAWT) with cambered tubercle leading edge (TLE) blades," Energy, vol. 175, pp. 278-291, 2019, doi: 10.1016/j.energy.2019.03.033.

[27] Z. Wang and M. Zhuang, "Leading-edge serrations for performance improvement on a vertical-axis wind turbine at low tipspeed-ratios," Appl. Energy, vol. 208, pp. 1184-1197, 2017, doi: 10.1016/j.apenergy.2017.09.034.

[28] Z. Wang, Y. Wang, and M. Zhuang, "Improvement of the aerodynamic performance of vertical axis wind turbines with leadingedge serrations and helical blades using CFD and Taguchi method," Energy Convers. Manag., vol. 177, pp. 107-121, 2018, doi: 10.1016/j.enconman.2018.09.028.

[29] J. Sony, Mukhtasor, R. W. Prastianto, and C. H. Jo, "Effects of demi-hull separation ratios on motion responses of tidal current turbines-loaded catamaran," Ocean Syst. Eng., vol. 10, no. 1, pp. 87-110, 2020. 